\title{
O PRINCÍPIO DA APLICAÇÃO JUSTA DAS LEIS DOS \\ CONFLITOS ARMADOS PARA \\ O HUMANISMO JURÍDICO NA PÓS-MODERNIDADE
}

The Application of the Principle of Fair Laws of Armed Conflict to Legal Humanism in Post-Modernity

El Principio de la Aplicación Justa de las Leyes de los Conflictos Armados para el Humanismo Jurídico en la Posmodernidad

Monica Paraguassu ${ }^{1}$

Resumo: O presente artigo apresenta um estudo sobre o princípio da aplicação justa de leis de guerra ou conflitos armados, internacionais ou não internacionais, a qual visa prevenir e reprimir violações graves de direitos humanos, considerando a teoria do humanismo jurídico e o contexto da pós-modernidade. Trata-se de estudo teórico jurídico, a partir de uma reflexão crítica sobre o princípio da aplicação justa das leis dos conflitos armados, que faz parte do direito internacional humanitário, sendo analisado segundo a relação entre as bases da teoria do humanismo ju-

1 Monica Paraguassu. Doutora em Direito e Mestre em Direito Penal e Política Criminal na Europa pela École Doctorale de Droit Comparé da Université Paris 1 - Panthéon-Sorbonne, França, (com Bolsa da Capes-Coordenação de Aperfeiçoamento de Pessoal de Ensino Superior). Professora Associada do Departamento de Direito Público e do Programa de Pós-graduação em Direito Constitucional, PPGDC, ambos da Faculdade de Direito da Universidade Federal Fluminense, UFF - Niterói - Rio de Janeiro - Brasil. monica.paraguassu.uff@gmail.com. 
rídico, da filosofia crítica e criminológica e da compreensão dos fatos das relações internacionais presentes na pós-modernidade. De modo a aprofundar a compreensão de tal princípio, busca-se estudar outros afins, como o princípio da separação entre jus ad bellum e jus in bello, da irretroatibilidade e da legalidade, segundo referências democráticas de tratamento igualitário. Considerando o cenário internacional anárquico da pós-modernidade, que fragiliza o humanismo jurídico, o texto é construído apontando duas perspectivas, seja a da cooperação e interdependência que pode explicar o direito de pretensões universais da ONU; seja a perspectiva da fragilidade de tal direito, por sua incapacidade de enfrentar os conflitos armados internos em razão da perda das referências do Estado Moderno sob influência da transformação do Estado Mercado.

Palavras-chave: Princípio da aplicação justa. Humanismo jurídico. Guerra justa. Conflitos armados. Direito internacional humanitário.

Abstract: This article presents a study on the principle of fair application of the laws of war or armed conflict, whether international or internal, aimed at preventing and punishing serious human rights violations, in light of the theory of legal humanism and the post-modern context. It is a legal theoretical study, based on critical reflection on the principle of fair application of the law of armed conflict, which is part of international humanitarian law. This law is analyzed based on the relationship between the bases of the theory of legal humanism, philosophy and critical criminological, and on an understanding of the facts of international relations present in post-modernity. In order to deepen the understanding of this principle, it studies the principle of separation between jus ad bellum and jus in bello, the non retroactivity criminal principle and legality principle, according democratic credentials of equal treatment. Considering the anarchic international scene of post-modernity, which weakens legal humanism, the text outlines two perspectives, whether from a perspective of cooperation and interdependence, which can explain the right to universal preten- 
sions by the UN, or from a perspective of the fragility of this right, due to its failure to address internal armed conflicts owing to the loss of the references of the Modern State, under the influence of the transformation of the Market State.

Keywords: Principle of fair application. Legal humanism. Fair war. Armed conflict. International humanitarian law.

Resumen: El presente artículo presenta un estudio sobre el principio de la aplicación justa de leyes de guerra o conflictos armados, internacionales o no internacionales, que intenta prevenir y reprimir violaciones graves de derechos humanos, considerando la teoría del humanismo jurídico y el contexto de la posmodernidad. Se trata de un estudio teórico jurídico realizado a partir de una reflexión crítica sobre el principio de la aplicación justa de las leyes de los conflictos armados, que forma parte del derecho internacional humanitario, y que será analizado según la relación entre las bases de la teoría del humanismo jurídico, de la filosofía crítica y criminológica y de la comprensión de los hechos de las relaciones internacionales presentes en la posmodernidad. Para profundizar la comprensión de tal principio se busca estudiar otros afines, como el principio de la separación entre jus ad bellum y jus in bello, de la irretroactividad y de la legalidad, según referencias democráticas de tratamiento igualitario. Considerando el panorama internacional anárquico de la posmodernidad que fragiliza el humanismo jurídico, el texto fue construido apuntando hacia dos perspectivas, la de la cooperación e interdependencia que puede explicar el derecho de pretensiones universales de la ONU, y la de la fragilidad de tal derecho, por su incapacidad de enfrentar los conflictos armados internos en razón de la pérdida de las referencias del Estado Moderno bajo influencia de la transformación del Estado Mercado.

Palabras clave: Principio de la aplicación justa. Humanismo jurídico. Guerra justa. Conflictos armados. Derecho internacional humanitario. 


\section{INTRODUÇÃO}

A proposta deste artigo é a de apresentar um estudo sobre o princípio da aplicação justa de leis de guerra ou de conflitos armados, internacionais ou não internacionais, considerando a perspectiva do humanismo jurídico em meio ao contexto da pósmodernidade. Para tanto, com base na teoria do direito internacional humanitário, no qual se insere o dito princípio e outros afins, como o da separação entre o jus ad bellum e o jus in bello, o da irretroatibilidade e o da legalidade, é feita uma reflexão crítica, isto é, transcendendo ao posto pelo positivismo e pelo construtivismo. Neste sentido, trabalha-se sobre o direito presente na Organização das Nações Unidas, na Cruz Vermelha e nas relações internacionais e sobre a perspectiva da filosofia crítica da criminologia destituída de um positivismo ideológico.

O humanismo jurídico, depois de longa trajetória, será estruturado pelas ideias Iluministas que vão compor o cenário da Revolução Francesa, representação de ambiguidades e contradições, porém conseguindo entoar princípios que vão servir para fortalecer o Estado Moderno. Esses princípios forjam um direito que tem sido desenvolvido no fórum internacional da Organização das Nações Unidas, construído em razão de duas guerras mundiais e de extrema violência que se sucederam no século $X X$.

Decerto, em consequência desse direito, o mundo viveu um período em que a possibilidade de conflito armado de âmbito internacional estava contida, na tensão do que foi conhecida como Guerra Fria, não obstante não conseguiu evitar conflitos armados internos, cujos grupos beligerantes apontam interesses particulares como justos e universais. Eé este o pesadelo a que, hoje, a comunidade internacional faz face, buscando, por meio do desenvolvimento de um direito que represente as tradições jurídicas, reagir contra tais conflitos internos, que produzem violações de direitos humanos.

Neste sentido, a comunidade internacional vê as referências da modernidade, baseadas na razão científica, em que tenta forjar seu direito e sustentar o humanismo jurídico, como insuficientes e frágeis para atuar em meio à linguagem pós-moderna de flexibilidade, volatilidade e incertezas, próprias do Estado Mercado. 
Trata-se de trabalho teórico indutivo, abordado a partir da técnica bibliográfica, mormente, dentro da perspectiva da professora Mireille Delmas-Marty, que avalia que o mito do humanismo jurídico está fragmentado e cujo sentido precisa ser restituindo. Não obstante, apontam-se as dificuldades em face ao contexto da pós-modernidade na reflexão de Jean-François Lyotard, contexto perpassado pela ambiguidade, que projeta tanto valores invariáveis próprios do positivismo, como no caso dos princípios, quanto as ideias do construtivismo que concebe uma realidade variável.

Não há direitos humanos fora da democracia e o direito internacional humanitário se constrói sobre esses fundamentos. Assim, o "princípio da aplicação justa das leis de guerra" preconiza que, nos conflitos armados, sejam internacionais ou internos, tais leis sejam aplicadas de maneira igual a todas as partes. Nesse sentido, procurase tratar o princípio da aplicação justa das leis de guerra como uma referência importante de tal construção. Para tanto, divide-se este artigo em três partes, em que serão abordados os seguintes aspectos: 1 - 0 princípio da aplicação justa das leis de guerra: insurgência não exclui o direito humanitário: 1.1 - Aplicação justa: princípios da necessidade e da humanidade e 1.2 - Princípio da separação entre o jus ad bellum e o jus in bello: o tratamento igual entre as partes; 2 - 0 princípio da irretroatibilidade da lei penal: não pode ser derrogado em caso de guerra ou em caso de outro perigo público ameaçador da vida da nação: 2.1 - Princípios da aplicação justa e da irretroatibilidade da lei penal e 2.2 Fragilização do humanismo jurídico; 3 - O humanismo jurídico em um sistema internacional anárquico: 3.1 - Do terror nacionalista ao terror descentralizado e desnacionalizado e 3.2 - A interface do humanismo jurídico com o político e o econômico.

\section{O PRINCÍPIO DA APLICAÇÃO JUSTA DAS LEIS DE GUERRA: INSURGÊNCIA NÃO EXCLUI O DIREITO HUMANITÁRIO}

\section{APLICAÇÃO JUSTA: PRINCÍPIOS DA NECESSIDADE E DA} HUMANIDADE

O princípio da aplicação justa das leis de guerra como princípio jurídico cumpre o papel de mediador entre os litigantes e articula os princípios da necessidade e da 
humanidade. Tais princípios já fundavam as Convenções de Haia de 1899 e de 1907 e as Convenções de Genebra em 1929, considerando o princípio da necessidade militar ou da proporcionalidade entre objetivos e meios, que determina o militarismo como medida de ultima ratio e o princípio da humanidade, que preconiza que o sofrimento desnecessário deve ser entendido como proibido. ${ }^{1}$

Duas das principais personalidades referências da construção do que se conhece, a partir dos séculos XVI e XVII, como direito internacional, Estado Moderno e humanismo, foram Alberico Gentili e Hugo Grotius. Gentili, em sua obra "O direito de guerra", define guerra como sendo "a justa contenda de armas públicas" e ao se ocupar da questão de que "a guerra não é coisa injusta", vincula a justiça da guerra à licitude, quando afirma que "é preciso ocupar-nos primeiramente da justiça da guerra, isto é, se é lícito fazê-la". ${ }^{2}$ E Grotius, em sua obra "O direito da guerra e da paz", diz que a guerra "é o estado de indivíduos, considerados como tais, que resolvem suas controvérsias pela força" ${ }^{3}$ e é considerada como justa quando respaldada em limites, tais como:

Não pode haver outra causa legítima da guerra, a não ser uma afronta recebida. O mesmo Agostinho escreve: "A iniquidade da parte contrária produz guerras justas". Ele se serviu do termo iniquidade por injúria, como se tivesse dito injustiça, querendo exprimir uma ação injusta. Esses eram os dizeres que o arauto romano carregava: "Eu vos tenho por testemunhas que este povo é injusto e que não cumpre o que deve". ${ }^{4}$

O direito internacional humanitário, identificado também como direito dos conflitos armados e como direito de guerra, estabelece as normas em conflito armado, internacionais e não internacionais, voltadas aos agentes públicos estatais ou grupos armados não estatais, enquadrando meios e métodos de guerra, buscando evitar violações graves de direitos humanos.

Em função dos horrores da II GM, vem sendo construído um direito em nível internacional, que tem como bússola o humanismo jurídico, para fazer face

1 ARTOV, Omer; GROSSMANN, Atina; NOLAN, Mary. Crimes de guerra, culpa e negação no século XX. RJ: Difel, 2005, p. 39.

2 ENTILI, Alberico. O direito de guerra. Ijuí: Ed. Unijuí, 2004, pp. 61 e 81.

3 GROTIUS, Hugo. O direito da guerra e da paz. Ijuí: Ed. Unijuí, 2004, p. 72.

4 GROTIUS, Hugo. O direito da guerra e da paz, p. 284. 
aos conflitos armados internacionais calcados em regras jurídicas objetivas positivistas, o que reforça a vigência de suas normas pela ratificação pelos Estados. No entanto, este cenário sofreu transformações. Com a Guerra Fria, os conflitos armados tornaram-se internos e cada vez mais com grupos formados por guerrilhas terroristas armadas, desconectados das forças convencionais, que não se submetem a regras internacionais.

Os conflitos armados internacionais expressam-se pela oposição de pelo menos dois Estados. Já os conflitos armados não internacionais ou internos se desenvolvem sobre o território de um Estado, tendo como oponentes os membros das FFAA regulares e outros grupos armados ou diferentes grupos armados entre eles.

O humanismo jurídico aplicado aos conflitos armados afirma-se em um princípio de direito identificado pela Cláusula Martens ${ }^{5}$, uma declaração do delegado da Rússia, Von Martens, na Conferência de Paz de Haya, de 1899, em que foi consagrada a exigência do respeito das leis da humanidade como um mínimo ético:

Enquanto que se forma um código mais completo das leis de guerra, as Altas Partes Contratantes julgam oportuno declarar que, nos casos não compreendidos nas disposições regulamentares adotadas por elas, as populações e os beligerantes permanecem sob a garantia e o regime dos princípios do direito das gentes preconizados pelos usos estabelecidos entre as nações civilizadas, pelas leis da humanidade e pelas exigências da consciência pública.

Abordar-se-á, então, o princípio da separação entre o jus ad bellum e o jus in bello, que permite a efetivação do princípio da aplicação justa das leis de guerra.

\section{PRINCÍPIO DA SEPARAÇÃO ENTRE O JUS AD BELLUM E O JUS IN BELLO: O TRATAMENTO IGUAL ENTRE AS PARTES}

O princípio da aplicação justa das leis de guerra é dependente do princípio da separação entre o jus ad bellum e o jus in bello. Há, portanto, a preocupação com o cumprimento da legalidade como limite aos conflitos armados, 5 TICEHURST, Rupert. La cláusula de Martens y el derecho de los coflictos armados. Revista Internacional de la Cruz Roja, 31/03/1997. Croix-Rouge, Comité International de la Croix-Rouge. 
independentemente da legitimidade particular que seja advogada pelas partes, e isto assim é como forma de impedir violações graves de direitos humanos. $O$ que falta para satisfazer à exigência moral de um verdadeiro senso de justiça, segundo Paul Ricoeur ${ }^{6}$ é:

Essencialmente, o estabelecimento de uma distância entre os protagonistas do jogo social _ distância entre a injustiça alegada e a represália apressada _, distância entre a imposição de um primeiro sofrimento pelo ofensor e a imposição de um sofrimento adicional aplicado pela punição. Mais fundamentalmente, o que falta à indignação é uma clara ruptura do elo inicial entre vingança e justiça.

A separação entre jus ad bellum e jus in bello infere a separação entre o que é considerado como a legalidade em termos de respeito às regras do uso da força e às regras humanitárias e o que é considerado como a legitimidade, em termos das causas dos beligerantes em que se baseiam os meios empregados.

Conforme explica Walzer?:

A realidade moral da guerra é dividida em duas partes. A guerra é sempre julgada duas vezes: primeiro, com referência aos motivos que os Estados têm para lutar; segundo, com referência aos meios que adotam. O primeiro tipo de julgamento é de natureza adjetiva: dizemos que uma guerra determinada é justa ou injusta. O segundo é de natureza adverbial: dizemos que a guerra é travada de modo justo ou de modo injusto. (...) Jus ad bellum exige que façamos julgamentos sobre agressão e autodefesa. Jus in bello, sobre o cumprimento ou a violação das normas costumeiras e positivas de combate.

Infere-se que tal princípio em questão tem como corolário o princípio do tratamento igual às partes, que é defendido por corrente dominante do direito internacional humanitário e preconizado pela Croix Rouge/Cruz Vermelha. A tese contrária, porém, insiste que seja considerada a importância de tratamento desigual das partes em função da causa que defendem, o que justificaria o emprego de meios contrários à legalidade.

Assim, de um lado, ergue-se o "princípio da aplicação justa das leis de guerra", preconizando que, nos conflitos armados, sejam internacionais ou internos, tais 6 RICOEUR, Paul. O justo 2. SP: Ed. Martins Fontes, 2008, pp. 251-252.

7 WALZER, Michael. Guerras justas e injustas. SP: Martins Fontes, 2003, p. 34. 
leis sejam aplicadas de maneira igual a todas as partes envolvidas diretamente nas hostilidades, independentemente, de suas razões. A tese contrária defende que os deveres das partes litigantes não são os mesmos e que, portanto, os que se consideram amparados por causa justificadora do conflito teriam direitos especiais. Os direitos e as obrigações em conflitos armados, que têm fundamento em um direito de guerra, deveriam, por conta de tal interpretação, ser aplicados de maneira desigual. Tal perspectiva é criticada pela Cruz Vermelha, nas palavras de Adam Roberts ${ }^{8}$, porque a ela se refere como não saudável, impossível de se concretizar eficazmente e podendo ter consequências perigosas.

A tese contrária se forja dentro das ambiguidades da pós-modernidade, por acentuar a construção da verdade por meio de desempenho conjuntural político, perspectiva que ignora os parâmetros da modernidade baseados na verdade da ciência por meio da razão.

A dita tese contrária é distorcida, considerando que o seu desdobramento expõe os direitos e os deveres dos combatentes à interpretação de acordo com o sujeito da ação e não em relação à conduta praticada. Tal perspectiva considera que condutas de autores que as respaldam em seus próprios critérios de justiça são condutas por isso legitimadas. Aí são aceitas as violações graves dos direitos humanos, haja vista que tais violações seriam interpretadas não em razão da legalidade, mas de acordo com os próprios critérios de justiça de cada grupo beligerante. As leis de guerra se destinam a todos que são participantes de algum modo dos conflitos armados, internacionais ou internos, uma vez que a segurança humana ${ }^{9}$ é a razão primeira das preocupações, portanto os direitos humanos. Não se tem com isso a intenção de eleger as referências de uma ordem hierárquica de sujeitos de direitos humanos, em que haja indivíduos que sejam considerados, em escala superior a de outros, como portadores de direitos, tais como o do direito à vida ou à integridade física.

O "princípio da aplicação justa" representa o tratamento dos beligerantes dentro do direito à igualdade, o que exclui o tratamento diferenciado entre 8 ROBERTS, Adam. L'application juste des lois de la guerre: um principe mis à rude épreuve.

Revue Internationale de la Croix-Rouge - Comité International de la Croix-Rouge, 872, 31/12/2008.

9 BUZAN, Barry; HANSEN, Lene. A evolução dos estudos de segurança internacional. SP: Ed. Unesp, 2012. 
os sujeitos. Reforça o direito ao tratamento igualitário dos sujeitos no conflito, sem levar em consideração circunstâncias desse, tais como quem deu início ao mesmo bem como se o conteúdo das causas da guerra tem base justa, portanto, conforme explica Roberts:

(...) não é relevante se uma força beligerante representa uma autocracia ou uma democracia, nem é relevante se representa governo de um simples país ou o desejo da comunidade internacional. ${ }^{10}$

Direitos e liberdades não podem ser usados como figura de retórica. Não obstante o humanismo jurídico está em crise, fragilizado na pós-modernidade, pela interface com o político, bem como com o econômico. Serão vistos, em seguida, exemplos que expõem a fragilidade do humanismo jurídico, porém também se pode que existe uma série de instrumentos que reforça, como no caso do princípio da irretroatibilidade da lei penal fora da hipótese de benefício ao réu, princípio este que não pode ser derrogado nem mesmo em caso de guerra.

\section{O PRINCÍPIO DA IRRETROATIBILIDADE DA LEI PENAL: NÃO PODE SER DERROGADO EM CASO DE GUERRA OU EM CASO DE OUTRO PERIGO PÚBLICO AMEAÇADOR DA VIDA DA NAÇÃO}

\section{PRINCÍPIOS DA APLICAÇÃO JUSTA E DA IRRETROATIBILIDADE DA} LEI PENAL

O princípio da aplicação justa das leis de guerra ou do conflito armado é um princípio, previsto no direito positivo, bem como aceito como princípio de direito internacional humanitário consuetudinário, compondo o jus cogens que preconiza a proteção ao gênero humano, por qualquer das partes beligerantes,

10 ROBERTS, Adam. The equal application of the laws of war: a principle under pressure. International Review of the Red Cross, volume 90, number 872, December 2008, p 932: "Under this principle, the laws of war (otherwise called jus in bello, law of armed conflict and international humanitarian law) apply equally to all those who are entitled to participate directly in hostilities _ and, so far as the application of the law is concerned, it is not relevant whether a belligerent force represents an autocracy or a democracy, nor is it relevant whether it represents the government of a single country or the will of the international community". 
independentemente das razões. Esse princípio censura, portanto, as violações de direitos humanos cometidas por qualquer um dos oponentes no conflito, sendo complementado pelos princípios penais da legalidade, da anterioridade e da retroatibilidade da lei mais benéfica.

Os princípios penais são exemplos do conservadorismo necessário para a segurança jurídica, ela também um princípio, serve de suporte para a efetivação do Estado Democrático de Direito na comunidade internacional. Dentre esses princípios estão o princípio da legalidade penal e o seu corolário, o princípio da anterioridade da lei penal, referências de ruptura contra o autoritarismo, assim como o princípio da irretroatibilidade da lei penal na ausência de benefício ao réu, princípios que asseguram que a lei serve à proteção do homem. ${ }^{11}$

O princípio da irretroatibilidade da lei penal não pode ser derrogado nem mesmo em caso de guerra ou em caso de outro perigo público ameaçador da vida da nação. ${ }^{12}$ Isto está literalmente previsto na Convenção Europeia de Salvaguarda de Direitos e de Liberdades Fundamentais, CESDH, estabelecida pelo Conselho da Europa, no artigo $7^{a}$ combinado com o artigo 15 parágrafo $2^{\circ}$, com base na Declaração Universal dos Direitos Humanos, em seu artigo 11.

O Tratado de Roma, que estabeleceu a Corte Penal Internacional, não se aplica de forma retroativa a fatos anteriores à sua vigência, portanto assegura o princípio de irretroatividade da lei penal, quando não beneficiar o réu. O Tratado datado de 1998 entrou em vigor apenas em 2002, ano em que foi ratificado pelo Brasil, por meio do Decreto 4388, que estabelece no seu artigo 11, item 1, sua competência ratione temporis: "o Tribunal só terá competência relativamente aos crimes cometidos após a entrada em vigor do presente Estatuto", assim como no artigo 24, item 1 , estabelece sua competência ratione personae: "nenhuma pessoa será considerada criminalmente responsável, de acordo com o presente Estatuto, por uma conduta anterior à entrada em vigor do presente Estatuto."

11 PARAguASSU, Monica. Presunção de inocência RJ: Eduff, 2011.

12 ROLLAND, P. Article 7, In: PETTITI, L-E\&DECAUX, E. \& IMBERT, P-H (sous la direction). La Convention européenne des droits de I'homme. Paris: Economica, 1999, pp. 293-303. TAVERNIER, P. Article 15, In: PETTITI, L-E\&DECAUX, E. \& IMBERT, P-H (sous la direction) La Convention européenne des droits de I'homme. Paris: Economica, 1999, pp. 489503. 
A Convenção Interamericana dos Direitos Humanos ou o chamado Pacto de São José da Costa Rica foi ratificado com a cláusula de reserva relativa à aplicação irretroativa, portanto apenas é aplicada para "fatos posteriores a 10 de dezembro de 1998", conforme consta do artigo $1^{\circ}$ do Decreto 4463/2002:

É reconhecida como obrigatória, de pleno direito e por prazo indeterminado, a competência da Corte Interamericana de Direitos Humanos em todos os casos relativos à interpretação ou aplicação da Convenção Americana de Direitos Humanos (Pacto de São José), de 22 de novembro de 1969, de acordo com art. 62 da citada Convenção, sob reserva de reciprocidade e para fatos posteriores a 10 de dezembro de 1998.

Passe-se, então, à exposição de caso que mostra a fragilidade do humanismo jurídico.

\section{FRAGILIZAÇÃO DO HUMANISMO JURÍDICO}

A construção seletiva de um direito à memória e à verdade histórica por meio de uma "ambivalente história de justiça" ${ }^{13}$ pode construir a figura da vítima naquele que foi também autor de violência, autor de crime, isto quando sendo posteriormente também vítima de um crime só identifica o que for conduta criminosa a do oponente, a do "outro". Os crimes cometidos por um lado são encobertos na memória pela consciência da vitimização, como no caso de alemães, incluindo população civil, que não se identificaram nos crimes nazistas, mas se identificaram como vítimas quando foram prisioneiros do Exército Vermelho:

(...) a memória do pós-guerra e a construção de uma mulher alemã vítima da guerra, dos bombardeios, da expulsão e do estupro do Exército Vermelho invasor dissiparam o papel ativo das jovens solteiras durante a guerra no front oriental. ${ }^{14}$

A tese contrária à aplicação justa das leis de guerra, considerando que não há separação entre jus ad bello e jus in bello, conforme já se viu, defende que meios 13 BARTOV, Omer; GROSSMANN, Atina; NOLAN, Mary. Crimes de guerra, culpa e negação no século $X \mathbf{X}, \mathrm{pp} 30-31$.

14 BARTOV, Omer; GROSSMANN, Atina; NOLAN, Mary. Crimes de guerra, culpa e negação no século $X X, \mathrm{pp} 30-31$. 
e métodos seriam válidos, ainda que as razões da violência fossem amparadas por critérios particulares de justiça do autor da violência. Tal tese denota sua incapacidade de combater violações dos direitos do homem.

Para ajudar nessa reflexão, vale-se de um caso atual polêmico, que tem inspirado entendimentos diversos e contrários, como é o da Comissão Nacional da Verdade (CNV). A problemática colocada neste subtítulo está presente neste caso, cujo estudo permite pontos de vista diversos, tais como o que afirma que, contrariando a própria lei que a instituiu, buscou apontar, de forma seletiva, apenas parte do conjunto de atores do quadro de violência à época. ${ }^{15}$ Perspectiva da seleção natural, se se utilizar de elementos da análise de Todorov ${ }^{16}$. Revela-se a reciprocidade da desumanização do inimigo, conforme o que diz Bauman ${ }^{17}$. Este caso serve aqui de exemplificação sobre a necessidade de coerência entre o arcabouço jurídico do humanismo jurídico, revelado no subtítulo anterior, e a necessidade de efetivação do mesmo diante de situações concretas.

Endossa-se a indagação de Delmas-Marty, "como restituir sentido ao mito do humanismo jurídico que mais parece a uma mistificação?" 18 Este exemplo da CNV é bem revelador da sociedade pós-moderna e do processo de fragilização, e até ridicularização por que passa o humanismo jurídico, em que o que está em questão não é a verdade, mas o desempenho do argumento para a prova, conforme se articula com a análise de Lyotard ${ }^{19}$.

A CNV foi instituída pela Lei 12528/2011, que definiu como sua função a efetivação do direito à memória e à verdade histórica e à promoção da reconciliação nacional, porém por meio da identificação de apenas parte de autores de violações durante o regime civil-militar, e para tanto, valendo-se

15 PARAGUASSU, M. Um retrocesso do humanismo jurídico. Site-Revista do Clube Militar, abril/2015.

16 TODOROV, Tzvetan. Os limites da justiça. In: CASSESE; DELMAS-MARTY (Orgs.). Crimes internacionais e jurisdições internacionais. Barueri, SP: Manole, 2004, p 45.

17 BAUMAN, Z. Modernidade e ambivalência. RJ: Zahar, 1999, p 55.

18 DELMAS-MARTY, M. Cours: Sens et non-sens de I'humanisme juridique - Humanisme et humanisme juridique: naissance et méamorfhoses du mythe da cátedra Études juridiques comparatives et internationalisation du droit. Collège de France, Paris 2010/2011: http://www. college-de-france.fr/site/mireille-delmas-marty/course-2011-01-05-14h00. htm: "Comment redonner sens à ce mythe de I'humanisme juridique qui ressemble trop souvent à une mystification?"

19 LYOTARD, Jean-François. O pós-moderno. RJ: José Olympio, 1986, p. 83. 
de motivações que demonstram as referências enunciadas anteriormente. Certamente que o propósito é o de atender à mudança da interpretação dos fatos, e com isso os próprios fatos, redefinindo os limites da verdade e por fim esta. Diz Bauman²0:

(...) um conceito bem fundamentado de verdade: é quando se diz a outros que eles estão em erro e portanto devem ou tem de mudar de opinião, assim confirmando a superioridade (leia-se: o direito de comando) do detentor da verdade (leia-se: o atribuidor de comando). (...) A verdade é, em outras palavras, uma relação social (como poder, propriedade ou liberdade): aspecto de uma hierarquia feita de unidades de superioridade e inferioridade;mais precisamente, um aspecto da forma hegemônica de dominação ou de uma pretensão de dominar pela hegemonia.

Também é possível verificar, sob um ponto de vista estritamente jurídico, que o relatório da CNV de dezembro de 2014 também apresenta problemas quanto às referências jurídicas que se utiliza. Indica o Tratado de Roma, como sua base jurídica para as imputações de responsabilidade aos indivíduos que acusa como responsáveis por violações de direitos humanos, contudo sem atentar para o impedimento definido pelo próprio tratado. Esse tratado versa que sua aplicação não pode ser retroativa à sua vigência, seja em termos de ratione personae e ratione temporis, conforme dito parágrafo anterior. $\mathrm{O}$ mesmo se diga em relação à Convenção Interamericana de Direitos Humanos, que também não admite aplicação retroativa a fatos anteriores a dezembro de 1998, conforme também dito anteriormente. Em vista disso, o relatório da CIDH sobre o caso Gomes Lund não procede, porque ignora tal condição.

O referido relatório da CNV procura indicar a responsabilidade penal por crime contra a humanidade. Cabe, contudo, antecipar que não foi ratificada, pelo ordenamento jurídico brasileiro, a Convenção sobre a imprescritibilidade dos crimes de guerra e dos crimes contra a humanidade de 1968. O crime contra a humanidade originariamente foi concebido em plena II GM, em 1915, em declaração assinada entre França, Inglaterra e Rússia contra os atos cometidos pelos turcos contra os armênios, posteriormente identificados como genocídio, embora ainda não oficialmente pela comunidade internacional. Esses atos 20 BAUMAN, Z. Modernidade e ambivalência, p 245. 
nunca foram julgados, tendo sido cometidos quando ainda não havia a Turquia, mas o Império Otomano que tinha relações com a Alemanha, então inimiga dos signatários da mencionada declaração.

Ao término da II GM, houve a assinatura da Carta de Londres, em 1945, que instituiu o Estatuto do Tribunal de Nuremberg, tendo então sido previsto o tipo penal do crime contra a humanidade. O Tribunal de Nuremberg tem aplicação apenas convencional para os quatro signatários _ França, Grã-Bretanha, EUA e URSS (Estados vencedores da guerra que já eram hegemônicos) e de acordo com o prescrito no artigo $6^{\circ}$ do estatuto, este instrumento se destinava ao julgamento dos autores materiais de crimes que tinham sido cometidos "por conta de países europeus do Eixo". Conclui-se, portanto, que este é instrumento circunscrito ao tempo e ao espaço, destinado unicamente ao julgamento dos vencidos nazistas. $E$ isto foi, inclusive, estimado pela justiça francesa que excluiu sua aplicação quando chamada para responsabilizar a França por crimes contra a humanidade, durante as guerras de descolonização na África. ${ }^{21}$

A partir da queda do muro de Berlim, houve as condições de entendimento por parte da comunidade internacional para o fortalecimento de um direito que seja uma linguagem comum, a ponto de chegar à edificação de jurisdições internacionais para julgar as violações graves de direitos humanos, na Iugoslávia e em Ruanda, nos moldes do Tribunal de Nuremberg de 1945. A necessidade de prevenir e reprimir violações graves de direitos humanos tem, também, conduzido à construção do quadro teórico da doutrina da responsabilidade de proteger, desenvolvendo o humanismo jurídico que forje intervenções de várias dimensões em Estados, inclusive, militares.

Passa-se à ultima parte deste trabalho, em que se abordará o sistema internacional anárquico, que precisa fazer valer sua crença em um sistema de cooperação e interdependência exposto no próprio humanismo jurídico, que tem interface com o político e o econômico.

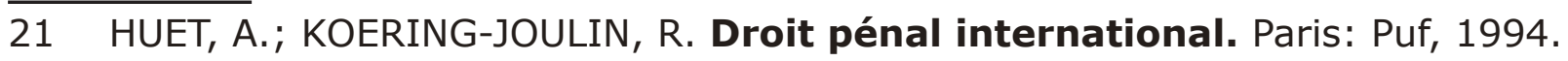




\section{O HUMANISMO JURÍDICO EM UM SISTEMA INTERNACIONAL ANÁRQUICO}

\section{DO TERROR NACIONALISTA AO TERROR DESCENTRALIZADO E DESNACIONALIZADO.}

O princípio da aplicação justa das leis de guerra ou do conflito armado, conforme já dito, preconiza o respeito ao gênero humano. Este princípio censura, portanto, as violações de direitos humanos cometidas por qualquer uma das partes envolvidas. Contrariando o princípio da aplicação justa das leis de guerra, a defesa da tese da justiça da desigualdade de tratamento entre as partes em conflito aponta que as forças amparadas pela legalidade têm o poder legítimo, em oposição às forças beligerantes ilegítimas, associadas a terrorismo, guerrilhas e ações violentas.

A legitimidade, contudo, também é vista de outra forma, quando um grupo insurgente ${ }^{22}$, defendendo causas segundo seus critérios de justiça, também, com a utilização da violência, como são os casos de guerrilhas terroristas, se identifica como portador de legitimidade do jus in bello. Estaria neste segundo caso a perspectiva de estado de exceção de Agamben, como um direito à resistência, algo entre democracia e absolutismo. ${ }^{23}$

As bases legais de nível internacional para aplicação do princípio da separação entre jus ad bellum e jus in bello estão, mormente, nas Convenções de Genebra de 1949 e seus Protocolos. O artigo $1^{\circ}$ da Convenção I de Genebra determina o respeito à Convenção pelas partes contratantes, que devem fazê-la respeitar em todas as circunstâncias, independentemente de ser o conflito ou a parte oponente considerados legítimos. $\mathrm{O}$ mesmo diz o artigo $3^{\circ}$, que é o principal instrumento jurídico de direito humanitário para o caso de conflito armado não internacional,

22 BONNET, Gabriel. Guerrilhas e revoluções. RJ: Civilização Brasileira, 1963, pp. 50-56.

23 AGAMBEN, Giorgio. Estado de exceção. 2. ed. SP: Boitempo, 2004, pp. 13 e 23. 
inclusive que surja sobre o território de uma das partes contratantes, afirma que cada uma das partes no conflito será obrigada a aplicar a Convenção.

Nesse sentido, os princípios sobre os objetivos e meios de uma guerra justa foram encampados pelas convenções humanitárias, segundo critérios de proporcionalidade e de razoabilidade. Estes princípios são visualizados no seguinte conjunto: princípios dos meios militares aplicados em situação limite ou como medida de ultima ratio; princípio da razoabilidade dos meios empregados para vencer a guerra e reparar os agravos sofridos; princípio da necessidade militar ou princípio da proporcionalidade, que afirma que o valor a ser garantido pela guerra seja proporcional ao valor sacrificado; princípio de proteção dos não combatentes contra os efeitos das operações militares; princípio do controle dos métodos de guerra; princípio do efeito duplo, que afirma que um mau efeito de uma boa conduta só é tolerável se houver boa intenção, se o efeito danoso for secundário e o resultado satisfatório deve ser maior que o mal acidental. ${ }^{24}$

Na realidade há certa confusão entre jus ad bellum e jus in bello. Identificamse, então, alguns exemplos: legítima defesa, uma causa justificante legal para intervenções militares, que se apoia ao mesmo tempo no jus in bello; violações de normas de direito humanitário pelas partes envolvidas têm motivado intervenções militares e sanções econômicas; participação dos membros dos grupos de oposição armados, considerados como membros das FFAA, como pessoal civil, ou como os civis que participam das hostilidades; necessidade de aplicação do princípio da proporcionalidade entre as regras do uso da força militar e a gravidade dos problemas no conflito. ${ }^{25}$

Viu-se no século XX o estabelecimento da violência da forma mais terrificante ou terrorista para atingir os fins, tanto por parte dos exércitos convencionais como dos não convencionais ou guerrilhas terroristas, tais como, ainda que em escalas diferentes em alguns dos exemplos, como nas guerras mundiais I e II, e nos conflitos armados da Manchúria, do Vietnã, do Golfo, na Revolução Russa e na Chinesa, e de grupos como ETA/Pátria Basca e Liberdade (Espanha), IRA/Exército Republicano 24 LIDER, Julian. Da natureza da guerra. RJ: Bibliex, 1987, p. 139.

25 HENCKAERTS, J-M. Étude sur le droit international humanitaire coutumier. Revue International de la Croix-Rouge, volume 87, Sélection française, 2005, pp 290-314. 
Irlandês, Brigadas Vermelhas (Itália), Guerrilha do Araguaia e outros grupos afins como AP/Ação Popular, ALN/Ação Libertadora Nacional, VPR/VAR-Palmares, MR8/Movimento Revolucionário 8/10 como outros tantos no Brasil, o Tupamaros (Uruguai) e o Sendero Luminoso (Peru) e o Baader-Meinhof (Alemanha).

O cenário hoje é ainda mais complexo, pois os conflitos armados, embora sendo internos e não internacionais, vêm tomando dimensões potencializadas, inclusive pela tecnologia e pela comunicação. Se o terrorismo do passado era nacionalista, hoje é descentralizado e desnacionalizado ou sem nacionalismo, como são al-Qaeda, DAESH-Estado Islâmico (Iraque/Síria), Boko Haram (Nigéria), Hezbollah (Líbano), as FARC/Forças Armadas Revolucionárias, a ELN/Exército de Libertação Nacional (ambos da Colômbia), que têm preocupado os Estados, inclusive, porque possuem relações com grupos marginais envolvidos com várias formas de tráfico.

Não obstante, o humanismo jurídico está fragilizado pela interface com o político e o econômico, no momento atual em que há tensão entre direitos humanos e forças de mercado, flexibilização da economia, hegemonia de sistemas jurídicos dominantes em regiões periféricas, como também grupos armados com pauta política apoiada na violência, sendo algumas encobertas por pretensões religiosas. Todos apontando seus particulares interesses com sendo justos e universais.

Esses grupos, ainda que com bandeiras de independência contra as hegemonias mundiais que visam fazer seus valores serem aceitos como universais, expressam-se de forma violenta, e sem uma pauta além da própria violência ${ }^{26}$. Neste sentido, suas práticas são na forma de conflitos armados de diversas ordens, sem respeito às regras mínimas do que se identifica como de direito internacional humanitário costumeiro ou convencional. Conforme o que escreveu Gentili: "ladrões não fazem guerra"27.

Pompônio e Ulpiano definem categoricamente: com piratas e ladrões não há guerra. E isso porque quem comete crime não se subtrai à jurisdição. Não se subtrai ao império da lei o súdito que se rebela

26 TROTSKY, Leon. Su moral y la nuestra. Buenos Aires: Ediciones El Yunque, 1983.

27 GENTILI, Alberico. O direito de guerra, p. 75. 
contra a lei, diz Baldo degli Ubaldi, e ninguém, diz Paulo, conquista prestígio por meio de delitos.

E também:

(...) por outra razão, não tem direito de guerra porque este descende do direito das gentes, do qual não gozam os malfeitores que o violam, Se direito é comunhão e pacto, está fora dele que se subtrai à comunhão e rompe o pacto do gênero humano (...).

Pode-se destacar, segundo referências comparativas de Walzer ${ }^{28}$, que esses grupos atuam como bandidos, porque são alheios a qualquer regra, em oposição aos antigos combatentes em guerras, tal como durante a Idade Média, quando havia "a fidalguia que distinguia os cavaleiros de meros bandidos ou malfeitores bem como de camponeses que empunhavam armas por necessidade". Diz ainda o autor que a fidalguia terminou sendo vítima da revolução democrática e da guerra revolucionária, posto que "a paixão popular sobrepujou a honra aristocrática". ${ }^{29}$ As práticas de violência de tais grupos são inenarráveis, à margem dos padrões mínimos de respeito em conflito armado, aquele comportamento que Walzer identificava ao soldado cuja vida nacionalizada pelo Estado Moderno transforma-o em vítima e não criminoso. ${ }^{30}$

\section{A INTERFACE DO HUMANISMO JURÍDICO COM O POLÍTICO E O ECONÔMICO}

O direito internacional humanitário por seus postulados quer revelar que as relações internacionais se inscrevem em meio a um campo teórico que se vale de uma compreensão de cooperação e interdependência entre os Estados, conforme teses das quais participam neoliberais como Keohane e $\mathrm{Nye}^{31}$, ainda que preservando suas bases em uma perspectiva realista ou soberanista. Assim, o direito internacional humanitário denota que as relações

28 WALZER, Michael. Guerras justas e injustas. SP: Martins Fontes, 2003, p. 57.

29 WALZER, Michael. Guerras justas e injustas. p. 58

30 WALZER, Michael. Guerras justas e injustas, p. 61.

31 KEOHANE, Robert; NYE, Joseph. Power and interdependence. 3rd ed. NY: Longman,2001, Chapter1, pp. 20-32. 
internacionais privilegiam a cooperação entre os Estados e, desse modo, são os Estados verdadeiros e importantes agentes no campo internacional, embora considerando que o sistema internacional é anárquico em uma geometria variável. Os Estados têm responsabilidade em relação à sua população, bem como à comunidade internacional.

As regras do humanismo jurídico têm emergido em um cenário que as confronta com as forças do mercado, estabelecendo-se uma tensão entre tais campos, em meio a uma geometria variável ${ }^{32}$. O humanismo jurídico parece fortalecido por regras de direito humanitário, de direito penal internacional, sem contudo conseguir um resultado progressivo, por exemplo, em termos de questões de direitos humanos nos países periféricos. Estes sufocados pela flexibilização das regras de mercado, em um mundo em transformação de Estado-Nação para Estado-Mercado como quer crer Philip Bobbitt ${ }^{33}$, se quiserem participar do jogo do comércio internacional têm que submeter suas regras de direito à lógica de um mercado da $l \mathrm{ei}^{34}$, sofrendo a hegemonia dos sistemas jurídicos dominantes. Do mesmo se diga sobre as deficiências do humanismo jurídico em face às dificuldades enfrentadas em relação aos refugiados, que buscam escapar das agruras vividas em países em recorrentes ditaduras e conflitos intestinos.

O direito internacional humanitário, compreendendo a noção de segurança humana, é um instrumento construído pela comunidade internacional de maneira a que possa reagir às violações de direitos humanos, porém não apenas justificada num direito de intervir, mas na doutrina da responsabilidade de proteger. Essa doutrina tem consubstanciado intervenções de tipos e graus diversos, arbitradas pelo Conselho de Segurança das Nações Unidas, políticas, diplomáticas e econômicas, inclusive militares, de acordo com o capítulo VII da Carta da ONU.

Tal dimensão dos poderes da comunidade internacional faz parte do entendimento, teoricamente, de um processo de universalidade que pressupõe um compartilhar de sentidos, de valores comuns, buscando dar aos direitos 32 DELMAS-MARTY, M. Cours: Sens et non-sens de I'humanisme juridique da cátedra Études juridiques comparatives et internationalisation du droit, lecionada no Collège de France, Paris, 2010/2011, p. 739, Collège de France: http://www.college-de-france.fr/media/mireille-delmas-marty/UPL580252029222612112_delmas_marty.pdf

33 BOBBITT, Philip. A guerra e a paz na história moderna. RJ: Ed. Campus, 2003.

34 DELMAS-MARTY. Três desafios para um direito comum. RJ: Lumen Juris, 2003, p 13. 
humanos uma perspectiva de uma linguagem comum. Não obstante, não se pode dizer que a perspectiva de um governo mundial esteja ao alcance imediato, como diz Nye ${ }^{35}$. Ainda assim, a ONU é uma instituição, que malgrado suas contradições, dentro de uma visão liberal, pode contribuir e tem contribuído para fazer face a conflitos, inclusive armados, em nome da proteção dos direitos do homem.

\section{CONSIDERAÇÕES FINAIS}

O direito internacional humanitário tem sido construído a partir da teoria do humanismo jurídico que sintetiza uma gama de valores, representados em princípios como o da aplicação justa das leis dos conflitos armados, respaldado em outros afins, como o da separação entre jus ad bellum e jus in bello, o da irretroatibilidade e o da legalidade, voltados ao tratamento igualitário e democrático, para prevenir e reprimir violações graves de direitos humanos. Não obstante, a violação da lei ou a sua negação, atitudes próprias de grupos não democráticos, que impõem interpretação particular fragilizando os direitos humanos, tem ocupado o cenário político-jurídico internacional, apesar de fóruns e instrumentos jurídicos que vêm sendo construídos no pós II GM.

Há uma série de exemplos hoje que mostra que os diversos matizes de razões e motivos em causa própria têm sido utilizados para explicar a interpretação da lei, a não submissão às regras de direitos humanitários, em contextos em que há insurgência e conflito armado não internacional. Em função disso, os grupos insurgentes que estão em conflito armado interno não identificam suas ações àquelas que estão submetidas às leis de conflito armado, considerando que as suas ações estariam respaldadas por uma legitimidade, por eles mesmos assim identificadas, portanto dentro de sua própria interpretação de guerra justa.

Este cenário é explicado por diversas correntes, ressaltando aqui, entretanto, duas perspectivas emblemáticas de um cenário internacional anárquico, na pós-modernidade, em que o humanismo jurídico se desenvolve, portanto, a de cooperação e interdependência e a do Estado Mercado. A perspectiva que

35 NYE JR., Joseph. Cooperação e conflito nas relações internacionais. SP: Ed. Gente, 2009, p. 339. 
aponta cooperação e interdependência se verifica na construção de um direito humanista de pretensões de universalidade, identificado como sendo o objetivo da ONU, já a outra perspectiva aponta a crise do Estado Nação, o Estado Moderno, que estaria passando por um período de perda de suas principais referências pela incapacidade de tratar os problemas aqui mencionados e, portanto, de transformação ao Estado Mercado, que já está sendo abalizado pelas próprias incertezas da pós-modernidade.

REFERÊNCIAS

AGAMBEN, Giorgio. Estado de exceção. 2. ed. SP: Boitempo, 2004.

BARTOV, Omer; GROSSMANN, Atina; NOLAN, Mary. Crimes de guerra, culpa e negação no século XX. RJ: Difel, 2005.

BAUMAN, Z. Modernidade e ambivalência. RJ: Zahar, 1999.

BOBBITT, Philip. A guerra e a paz na história moderna. RJ: Ed. Campus, 2003.

BONNET, Gabriel. Guerrilhas e revoluções. RJ: Civilização Brasileira, 1963.

BUZAN, Barry; HANSEN, Lene. A evolução dos estudos de segurança internacional. SP: Ed Unesp, 2012.

DELMAS-MARTY, Mireille. Cours: Sens et non-sens de I'humanisme juridique Humanisme et humanisme juridique: naissance et méamorfhoses du mythe da cátedra Études juridiques comparatives et internationalisation du droit. Collège de France, Paris 2010/2011: http://www.college-de-france.fr/site/mireille-delmas-marty/course-201101-05-14h00.htm

DELMAS-MARTY, M. Cours: Sens et non-sens de I'humanisme juridique da cátedra Études juridiques comparatives et internationalisation du droit, lecionada no Collège de France, Paris, 2010/2011, página 739, Collège de France:http://www.college-de-france.fr/media/mireilledelmas-marty/ UPL580252029222612112_delmas_marty.pdf

DELMAS-MARTY, M. Três desafios para um direito comum. RJ: Lumen Juris, 2003. 
GENTILI, Alberico. O direito de guerra. Ijuí: Ed. Unijuí, 2004.

GROTIUS, Hugo. 0 direito da guerra e da paz. Ijuí: Ed. Unijuí, 2004.

HENCKAERTS, J-M. Étude sur le droit international humanitaire coutumier. Revue International de la Croix-Rouge, volume 87, Sélection française, 2005.

HUET, A.; KOERING-JOULIN, R. Droit pénal international. Paris: Puf, 1994.

KEOHANE, Robert; NYE, Joseph. Power and interdependence. 3rd ed. NY: Longman, 2001.

LIDER, Julian. Da natureza da guerra. RJ: Bibliex, 1987.

LYOTARD, Jean-François. O pós-moderno. RJ: José Olympio, 1986.

NYE JR., Joseph. Cooperação e conflito nas relações internacionais. SP: Ed. Gente, 2009.

PARAGUASSU, Monica. Um retrocesso do humanismo jurídico. Site-Revista do Clube Militar, 2015.

PARAGUASSU, Monica. Presunção de inocência RJ: Eduff, 2011.

RICOEUR, Paul. O justo 2. SP: Ed Martins Fontes, 2008.

ROBERTS, Adam. L'application juste des lois de la guerre: um principe mis à rude épreuve. Revue Internationale de la Croix-Rouge - Comité International de la Croix-Rouge, 872, 31/12/2008.

ROBERTS, Adam. The equal application of the laws of war: a principle under pressure. International Review of the Red Cross, volume 90, number 872, December 2008.

ROLLAND, P. Article 7. In: PETTITI, L-E\&DECAUX, E \&I MBERT, P-H (sous la direction). La Convention européenne des droits de I'homme. Paris: Economica, 1999.

TAVERNIER, P. Article 15. In: PETTITI, L-E\&DECAUX,E. \& IMBERT, P-H (sous la direction) La Convention européenne des droits de l'homme. Paris:Economica, 1999.

TICEHURST, Rupert. La cláusula de Martens y el derecho de los coflictos armados. Revista Internacional de la Cruz Roja, 31/03/1997. Croix-Rouge, Comité International de la Croix-Rouge.

TODOROV, Tzvetan. Os limites da justiça. In: CASSESE; DELMAS-MARTY (Orgs.). Crimes internacionais e jurisdições internacionais. Barueri, SP: Manole, 2004. 
TROTSKY, Leon. Su moral y la nuestra. Buenos Aires: Ediciones El Yunque, 1983.

WALZER, Michael. Guerras justas e injustas. SP: Martins Fontes, 2003.

Recebido em: set/2015

Aprovado em: abr/2016 